\title{
Analysis of Impact of Gust Angle and Velocity on the Position of Stagnation Point
}

\author{
Michał Frant ${ }^{1 *}$, Adam Kozakiewicz ${ }^{1}$, Stanisław Kachel ${ }^{1}$ \\ 1 Faculty of Mechatronics, Armament and Aerospace, Military University of Technology, ul. gen. Sylwestra \\ Kaliskiego 2, 00-908 Warszawa 46, Poland \\ *Corresponding author's e-mail: michal.frant@wat.edu.pl
}

\begin{abstract}
This paper presents the selected issues regarding the design of a complex object of a turbine jet engine inlet duct model for the purposes of numerical analysis related to the phenomenon of inlet vortex formation. The authors described the process of discretisation in the matter in question and presented certain guidelines for preparing and conducting discretisation of the computational area. The authors presented an exemplary test findings analysis to verify the accuracy of the object's shape, computation grid as well as the selection of the boundary conditions and solution algorithm. The main part of the paper regards the analysis of changes in the location of the vortex (point of stagnation) based on an examination of the impact related to the changes in the velocity and inlet and gust angles. The authors sought to determine the areas and regularity of points of stagnation.
\end{abstract}

Keywords: inlet vortex, numerical fluid mechanics, turbine jet engine

\section{INTRODUCTION}

The authors analysed the engine air inlet of the MiG-29 fighter aircraft (Fig. 1). The selected inlet arrangement is fuselage-shielded. The inlets of this type show significant susceptibility to ingesting foreign objects from the runway surface due to the inlet vortex formation. As demonstrated by the statistical data, including the US Air Force (Fig. 2), it is a major cause of the jet engine damage.

As shown by the statistical data, the occurrence of jet engine damages due to the ingestion of foreign objects is increasing. The trend poses a problem both for the air force and civil aviation. The inlet vortex problem was a subject of experimental $[8,9]$ and numerical research $[5,7,10,11]$.

\section{Model design}

The virtual model of the MiG-29 engine inlet system (Fig. 1) was built with the use of the aircraft's CAD geometry based on reverse engineering. The geometry had to be specially prepared so that it could be used in numerical flow simulations. In this light, the work was conducted in the following stages:

- import of the geometry from an external CAD file

- selection of the computational area

- assessment of the admissibility and possibility of simplifying the object for the purpose of numerical analysis;

- discretisation of the object inlet and discretisation of the computational domain

- setting of the boundary conditions and export to the solver.

The geometry was imported from an external CAD file into the Gambit preprocessor. Next, a "clean-up" operation was performed to remove a number of relatively small planes (compared to others) from the object, as they greatly hinder the process of constructing a surface grid on the object. The operation resulted in generating a discretised surface of the object to be examined (Fig. 3). 


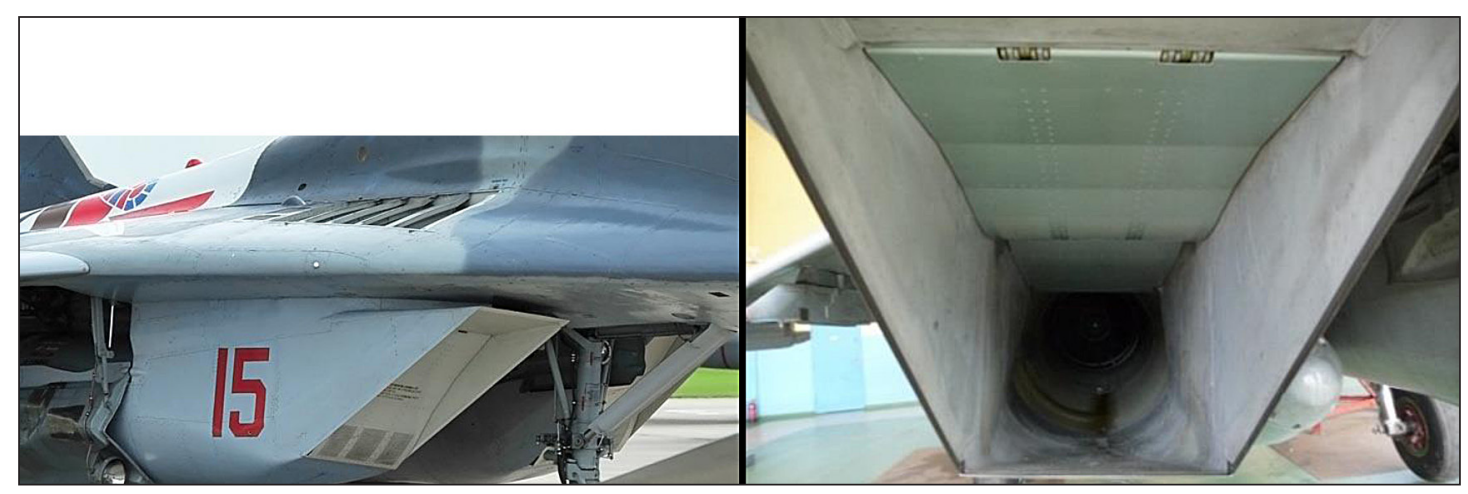

Fig. 1. Examined fuselage-shielded air inlet configuration

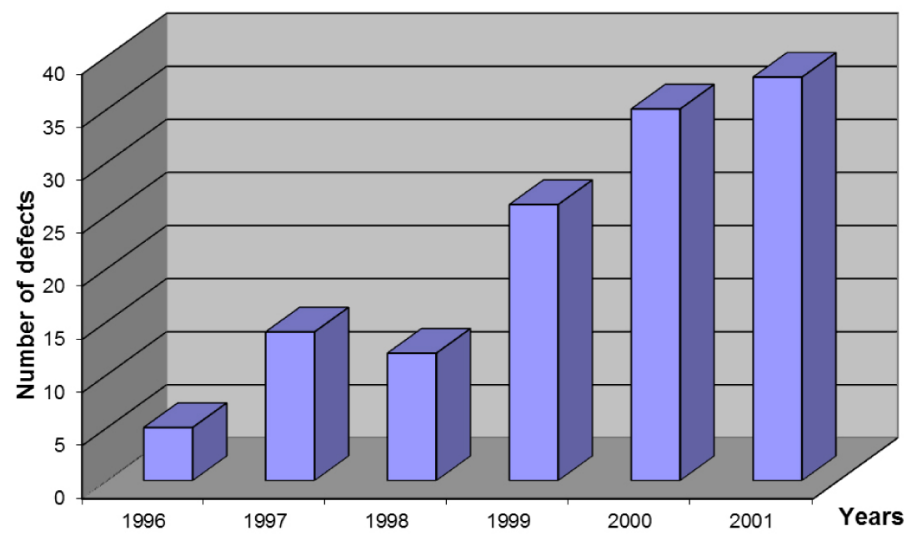

Fig. 2. Number of jet engine damage due to ingestion of foreign objects in the US Air Force in 1996-2001 [4]

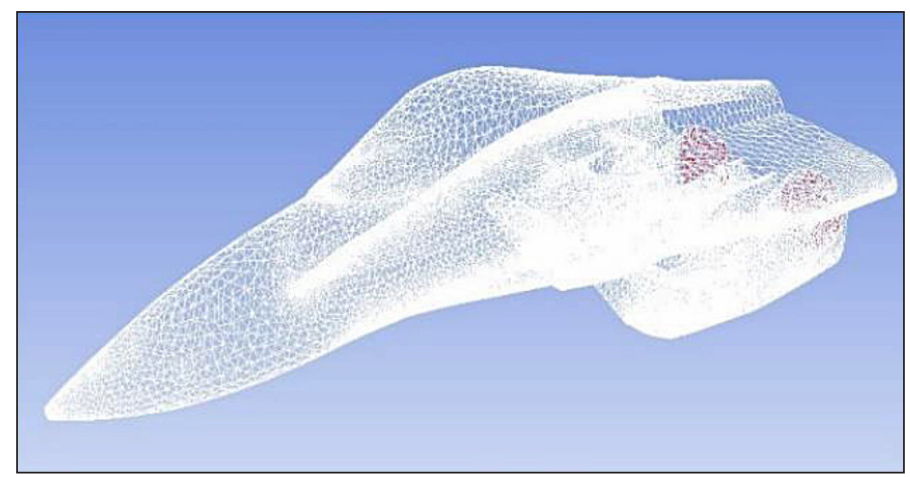

Fig. 3. View of surface discretisation of the examined object

Since the object was geometrically complex, the chosen design was a triangular surface grid.

The size of the computational domain was selected on the basis of earlier experiences from other similar studies. In this study, the computational domain is a $20 \times 10 \times 10 \mathrm{~m}$ cuboid (Fig. 4). The virtual object was positioned so that the fuselage nose was at the origin of coordinates. Next, a smaller domain $10 \times 5 \times 3.8 \mathrm{~m}$ (Fig. 5) was isolated from the large one to contain the examined object. That operation provided for generating a more dense grid in the inner domain, which is essential for computation accuracy, with a less dense grid in the remaining area to avoid excessively large parameter gradients.

The next step involved discretising the planes that define the outer sub-area and the inner area. Triangular grids were used also in this case. With all planes discretised, the discretisation of the computational domain was commenced with the use of tetrahedral elements. The complete grid had nearly 1,350,000 finite volumes.

At the last stage, the boundary conditions were set. A free-stream boundary condition (pressure 


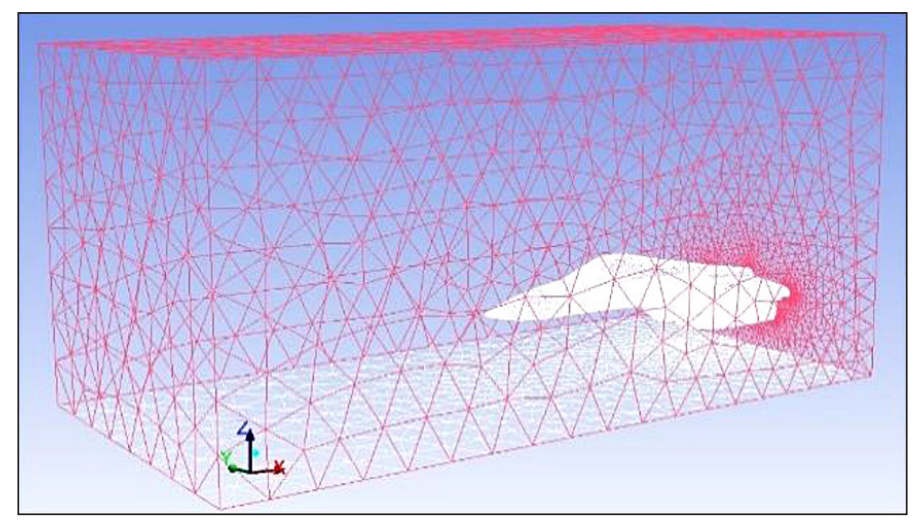

Fig. 4. View of the outer area discretisation

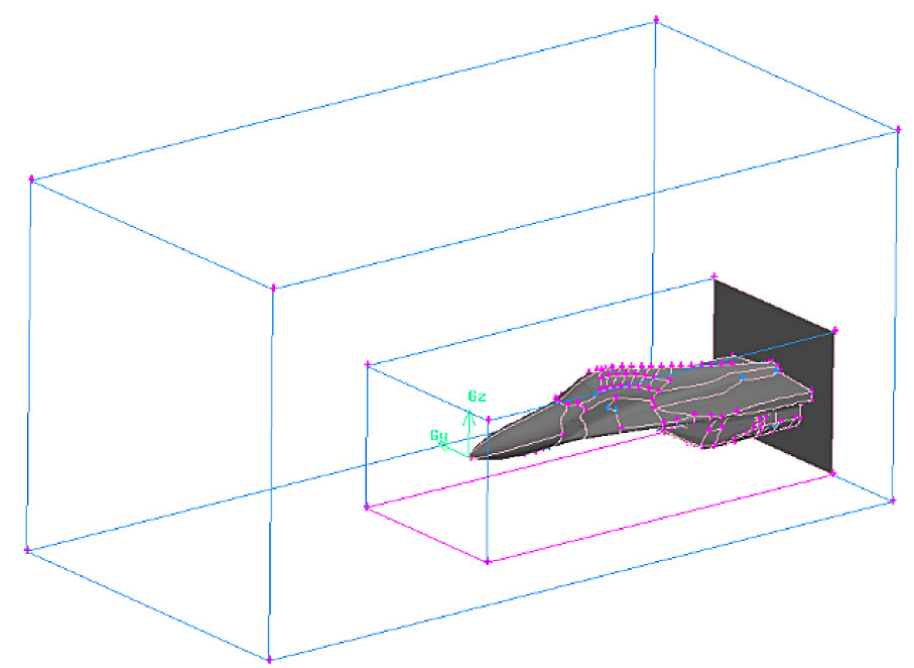

Fig. 5. View of the computational domain with the isolated sub-domain

far field) was set for the lateral planes and the upper plane of the outer domain. A wall boundary condition was set for the bottom plane (the bed) of the outer domain. A wall boundary condition was set also for the surfaces that outlined the examined object. A pressure outlet boundary condition was set for the surfaces outlining the engine compressor inlets. Finally, the resulting grid was exported to the Ansys Fluent solver.

The calculations were carried out with the commercial computational package CFD Ansys Fluent. The package is based on the finite volume method. An indisputable advantage of this method is that it provides for building non-orthogonal and non-uniform computational grids, which is essential for computational tasks involving the objects of complex shapes [3].

The method is based on the direct discretisation of the equations expressing conservation laws in the physical space; therefore, the following conservation equations represent the starting point [3]:
- mass conservation equation (continuity equation)

$$
\frac{\partial}{\partial t} \iiint_{V} \rho d V+\iint_{S} \rho V_{n} d S=0
$$

- momentum conservation equation

$$
\frac{d}{d t}\left(\iiint_{V} \rho \nabla d V\right)=\iint_{S} \mathrm{p}_{n} d S+\iiint_{V} \rho \overrightarrow{\mathrm{F}}_{\mathrm{m}} d V
$$

- energy conservation equation

$$
\begin{array}{r}
\quad \frac{d}{d t}\left[\iiint_{V} \rho\left(c_{v} T+\frac{V^{2}}{2}\right) d V\right]=\iint_{S} p_{n} v d S+ \\
+\iiint_{V} \rho \vec{F}_{m} \vec{V} d V+\iint_{S} \dot{a}_{n} d S+\iiint_{V} \dot{q}_{m} \rho d V
\end{array}
$$

where: $V$-volume;

$S$ - surface area;

$\dot{q}_{n}$ - surface density of the heat stream;

$\dot{q}_{m}-$ heat stream density per fluid mass unit. 
In order to simplify further transformations, the three aforementioned equations can be written as:

$$
\frac{\partial}{\partial t} \iiint_{V} \vec{\Phi} d V+\iint_{S} \vec{H} d S=\iiint_{V} \vec{R} d V
$$

where: $\Phi, H, R$ are column vectors:

$$
\vec{\Phi}=\left[\begin{array}{c}
\rho \\
\rho \vec{v} \\
\rho e
\end{array}\right] ; \vec{H}=\left[\begin{array}{c}
\rho v_{n} \\
\rho \vec{v} v_{n} \\
(\vec{v} \vec{n}) \rho e
\end{array}\right]
$$

$\vec{R}=\left[\begin{array}{c}0 \\ \rho \vec{F}_{m}+\operatorname{div} \Pi \\ \rho \vec{F}_{m} \vec{v}+\dot{q}_{m} \rho+\operatorname{div}(\Pi \vec{v})+\operatorname{div}(\lambda \operatorname{grad} T)\end{array}\right]$

where: $\Pi$ - surface stress tensor [3]

$\lambda$-thermal conductivity coefficient

Vector $\boldsymbol{\Phi}$ is a state vector, and its components are mass, momentum and the total energy of unit volume. These are basic characteristics describing the physical state of a fluid. The first part of the left side of equation (4) defines the rate of change of this state in time induced by external sources. Those sources cause changes also in the momentum and energy. Surface integral in (4) is a convection element and it defines streams of these quantities over the external surface. The part on the right side of the equation is a source element and it contains the diffusion elements under the divergence sign.

Further, the aforementioned equations are averaged in accordance with the formulas in [1, $2,5,12]$ and the resulting equations are known as Reynolds equations. These equations were applied to solve the problem in question. It should be noted that the aforementioned averaging makes the initially closed system of equations an open one, for it lacks the 6 complementary relations defining the components of the turbulent stress tensor [1]. Therefore, it becomes necessary to apply the turbulence models.

The preliminary test computations were carried out for the pressure range from $50000 \mathrm{~Pa}$ to $98000 \mathrm{~Pa}$ in the compressor inlet plane in the engine flow duct.

The preliminary tests were aimed at verifying the correctness of the virtual object, computational grid and boundary conditions. No computational grid adaptation was carried out during the preliminary computational tests. The computations were made only for the Spalart-Allmaras turbulence model at zero external flow velocity.

During the preliminary computational tests, the mass flow rates ranged from 31 to $121 \mathrm{~kg} / \mathrm{sin}$ the engine compressor plane.

The subsequent stage involved serial computations for variable quantities of the inflow velocity and gust angles. The computations were made for a single pressure value in front of the fan, equal to $85700 \mathrm{~Pa}$.

\section{RESULTS OF THE COMPUTATION}

This section of the study focuses on the phenomenon of the inlet vortex formation in the turbine jet engine inlet model of the MiG-29 aircraft. In the cases analysed, the aircraft model was immobilised and the investigators analysed the impact of gust direction and velocity on the formation of the inlet vortices. A total of 48 cases were analysed for varying gust velocities at $\mathrm{Ma}$ $=0.0025$ (i.e. approx. $0.87 \mathrm{~m} / \mathrm{s}$ ), $\mathrm{Ma}=0.005$ $(1.73 \mathrm{~m} / \mathrm{s})$, and at the gust angles in the vertical plane of $\alpha=0^{\circ},-5^{\circ},-10^{\circ},-15^{\circ}$, and at gust angles in the horizontal plane of $\beta=0^{\circ}, 15^{\circ}, 30^{\circ}, 45^{\circ}, 60^{\circ}$, $90^{\circ}$. The definition of the vertical gust angle $\alpha$ and horizontal gust angle $\beta$ is shown in Figure 6.

a) $\alpha$-gust direction angle in the XZ plane

b) $\beta$-gust direction angle in the XY plane.

A selected computational case in the numerical analysis of the vortex position (point of stagnation) in the function of the aforementioned groups of parameters is shown in Figures 7 and 8.

\section{Analysis of stagnation point positions}

The analysis of stagnation point migration was conducted for two groups of parameters. One group involved the cases of gust force, as mentioned in section 3, i.e. the gust velocity of $\mathrm{Ma}=0.0025$ and $\mathrm{Ma}=0.005$. The other group of parameters was related to the gust direction defined by angles $\alpha$ and $\beta$ (Fig. 6). The numerical analysis was to establish the impact of those parameters on changes in the stagnation point position. The position was established through distance $r$ and angle $\eta$ relative to the longitudinal axis of the inlet duct.

The first group of results (Fig. 8-10) related to the gust velocity of $\mathrm{Ma}=0.025$. In this case, the gust direction angles $\beta$ that produced the 

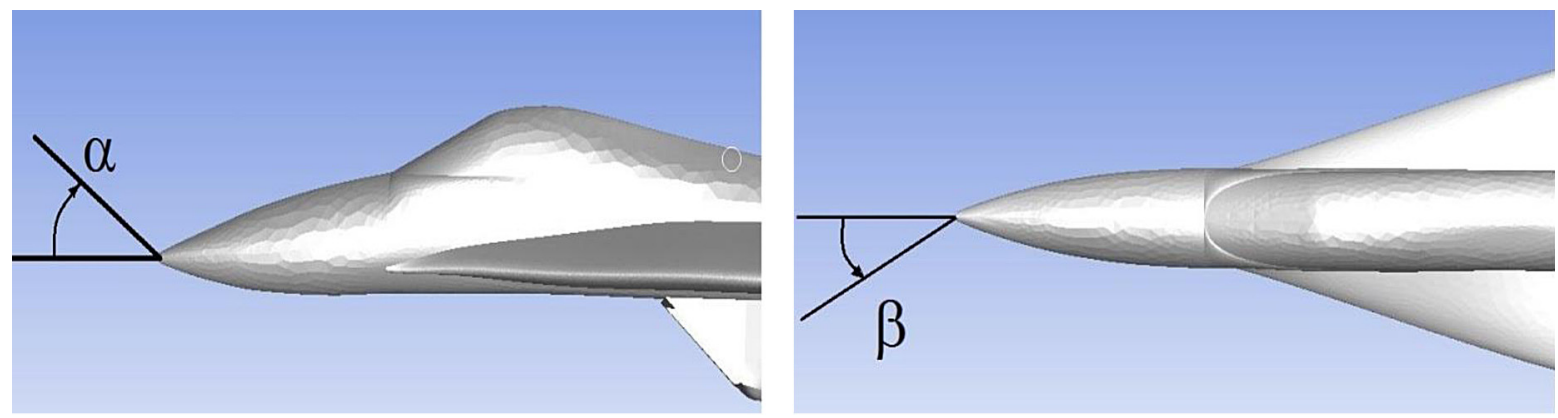

Fig. 6. Definition of gust angles in the examined object:

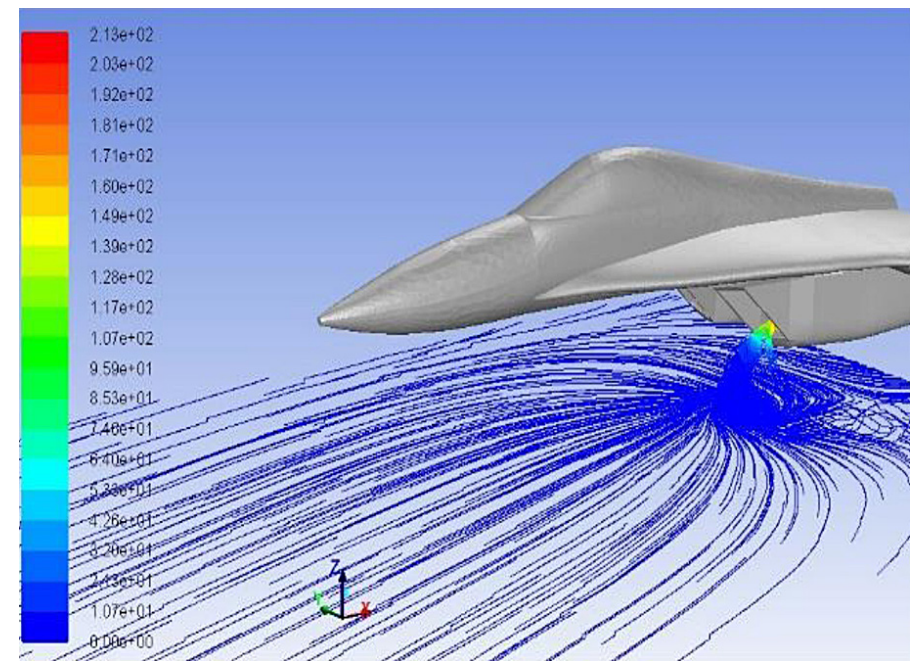

Fig. 7. Streamline flow for $\mathrm{Ma}=0.0025 \beta=15^{\circ}$ and $\alpha=0^{\circ}$

vortex and the line and point of stagnation ranged from 5 to 60 degrees at a varying inflow angle $\alpha$ from 0 to 15 degrees. While analysing the results, one can notice a certain regularity regarding the migration of the point of stagnation in relation to the relative radius $r / d$ (the distance of the position to the effective diameter of the inlet), at all $\alpha$ variants.

For all cases of angles $\alpha$, the curve of stagnation point positions vs. the gust angle $\beta$ gives the minimum distance relative to the centre of the surface of the engine inlet system. The range of the minimum distance is for $\beta$ from $25^{\circ}$ to $40^{\circ}$. The distance started to increase at both ends of that range. In the case of the highest value of gust inflow angle $\alpha=15^{\circ}$ the range of $\beta$ in which the vortex was formed (point of stagnation) became narrower (from $15^{\circ}$ to $45^{\circ}$ ).

In all cases, the minimum value of the relative radius i.e. the stagnation point position relative to the engine inlet was approximately $r / d=0.5$, while the maximum value was nearly three times higher and amounted to 1.42. The maximum distance $r / d$ of the stagnation point was at the maximum gust inflow angle $\alpha=15^{\circ}$ for $\beta=45^{\circ}$. In the case of the baseline angle $\alpha=0^{\circ}$, the points of stagnation (vortices) formed together with the line of stagnation in the widest value range of $\beta$ (from $5^{\circ}$ to $60^{\circ}$ ) and the largest diversity of the distance $r / d$ from 0.58 to 1.34 .

In addition, the authors described the changes in the stagnation point position angle. The results are shown in Figure 10. The angular position of the point of stagnation changed within the range from $-35^{\circ}$ to $-79^{\circ}$. The range of angular changes in the stagnation point position depends substantially also on the gust direction angle $\alpha$ in plane XZ (Fig. 6). The smallest changes in the angular position were recorded at $\alpha=5^{\circ}$, where the smallest changes in the distance were achieved (Fig. 8). For $\alpha=$ $0^{\circ}$, the largest change in the angle at the ends of the range of vortex formation (for $\beta=10^{\circ}$ and $60^{\circ}$ ). The largest changes in the angular position were achieved for $\alpha=10^{\circ}$. The largest regularity was achieved in the range of $\beta$ from $15^{\circ}$ to $45^{\circ}$, except for $\alpha=10^{\circ}$, and that as the range of the lowest $r / d$ distance values. 


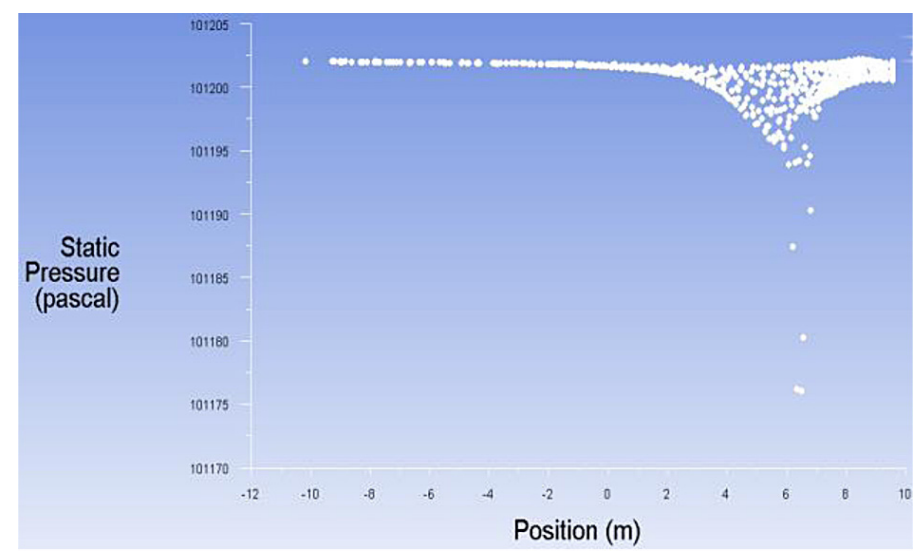

Fig. 8. Underpressure zone for $\mathrm{Ma}=0.0025 \beta=15^{\circ}$ and $\alpha=0^{\circ}$

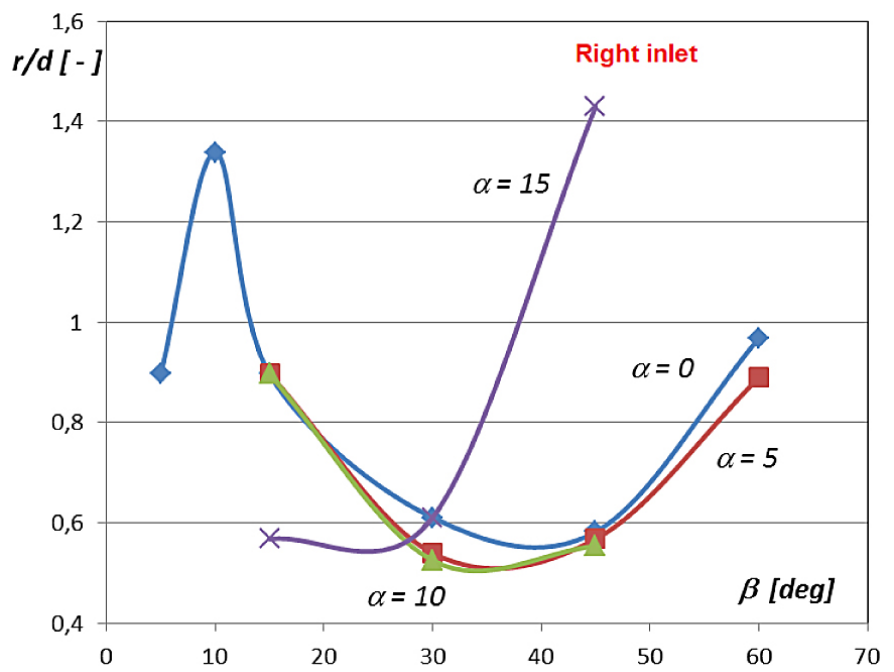

Fig.9. Change in the distance $r / d$ of the stagnation point position vs. gust direction $\beta$ and gust inflow angle $\alpha$, at $\mathrm{Ma}=0.0025$

The analysis of the stagnation point position on the surface in front of the inlet based on aggregated coordinates, i.e. the distance $\mathrm{r} / \mathrm{d}$ from the inlet and the position angle $\eta$ to the longitudinal axis of the engine, is shown in Figure 10. Similarly to the previous charges, the largest linear shifts relative to the engine inlet were achieved for the smallest angle of $\alpha=0^{\circ}$ and the largest angle of $\alpha=15^{\circ}$. One can notice a zone of increased susceptibility to vortex formation for all cases of gust inflow angle $\alpha$. These points are located within the area of distance $r / d$ from 0.5 to 0.9 and angle $\eta$ from $-60^{\circ}$ to $-65^{\circ}$.

An increase in the gust velocity, expressed in Mach, up to $\mathrm{Ma}=0.005$ had an impact on shifting the vortex away from the inlet i.e. on increasing the value of $r / d$ (point of stagnation - Fig. 11). This significant difference compared to the first gust case $(\mathrm{Ma}=0.0025)$, i.e. the wider range of stagnation point formation, is due to the increased gust force. Another difference regards an increase in the range of angles $\beta$ of vortex formation from $0^{\circ}$ to $90^{\circ}$, whereas in the first case (Fig. 8) the range was $0^{\circ}$ to $60^{\circ}$. With gust of $M \alpha=0.0025$, the vortex formed within the $\mathrm{r} / \mathrm{d}$ range from 0.5 to 1.42 , whereas for $\mathrm{M} \alpha=0.005$ the range $r / d$ rose from 0.25 to 3 . An increase in gust angle $\beta$ (in plane XY) from $30^{\circ}$ to $60^{\circ}$ for all cases of $\alpha$ caused a decrease in the distance $r / d$ of the vortex from the inlet. The gusts at angles above $\beta=$ $60^{\circ}$ show no regularity of changes in the stagnation point position vs. angle $\alpha$ i.e. for angle $\alpha=0^{\circ}$ there was no significant change in the distance, for $\alpha=5^{\circ}$ the distance decreased, and for the largest inflow angle of $\alpha=10^{\circ}$ the situation was opposite to the previous angle $\alpha=5^{\circ}-$ the linear distance grew several times to $r / d>3$.

The profile of changes in the stagnation point position vs. gust direction for the increased $\mathrm{Ma}$ $(\mathrm{M} \alpha=0.005)$ is shown in Figure 12. Compared 


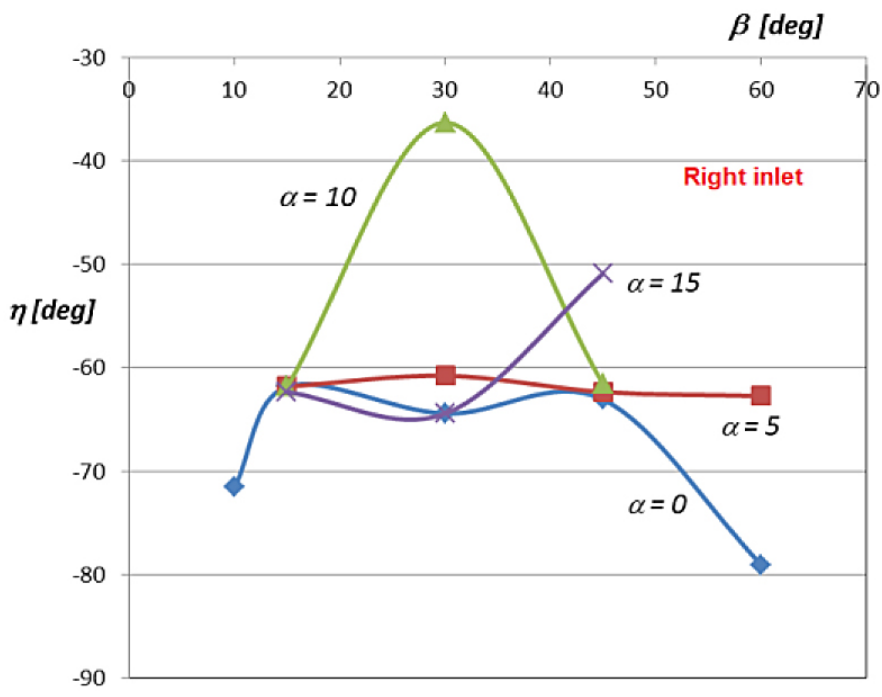

Fig. 10. Change in the stagnation point position angle vs. gust direction $\beta$ and gust direction angle $\alpha$, at $\mathrm{Ma}=0.0025$

to the baseline case (Fig. 9), i.e. $\mathrm{Ma}=0.0025$ where no vortices formed in the range $\beta=0^{\circ} \div$ $10^{\circ}$, vortices did form in this case. Moreover, for $\beta>60^{\circ}$ in the baseline case there were no vortices, whereas vortices did form in this case. While analysing this gust case, one can say that for the gust direction angles above $\beta=10^{\circ}$ the profile of changes in the stagnation point position angle $\eta$ starts to change. For $\alpha \geq 10^{\circ}$ the curve becomes parabolic along with the process of migration of the stagnation point from one longitudinal side of the inlet (i.e. for $\eta=0^{\circ}$ ) to the other. The largest change in the position angle in the examined range of $\beta$ was achieved for $\alpha=10^{\circ}$, with $\beta=90^{\circ}$.
No point of stagnation was achieved for the same value of $\beta$ and $\alpha=15^{\circ}$.

The result of combining both linear $r / d$ and angular $\eta$ coordinates to demonstrate the migration of the stagnation point for the stronger gust of $M \alpha=0.005$ is shown in Figure 13. In this gust case, there was a change in the zone of stagnation point positions compared to the results shown in Figure 10. In addition, the vortex positions moved away from the inlet, which can be clearly seen and was discussed in the characteristic of $r / d=$ $f(\beta ; \alpha)$ - Figure 11. Another important difference was the general migration of stagnation points to the other side of the engine inlet axis compared to

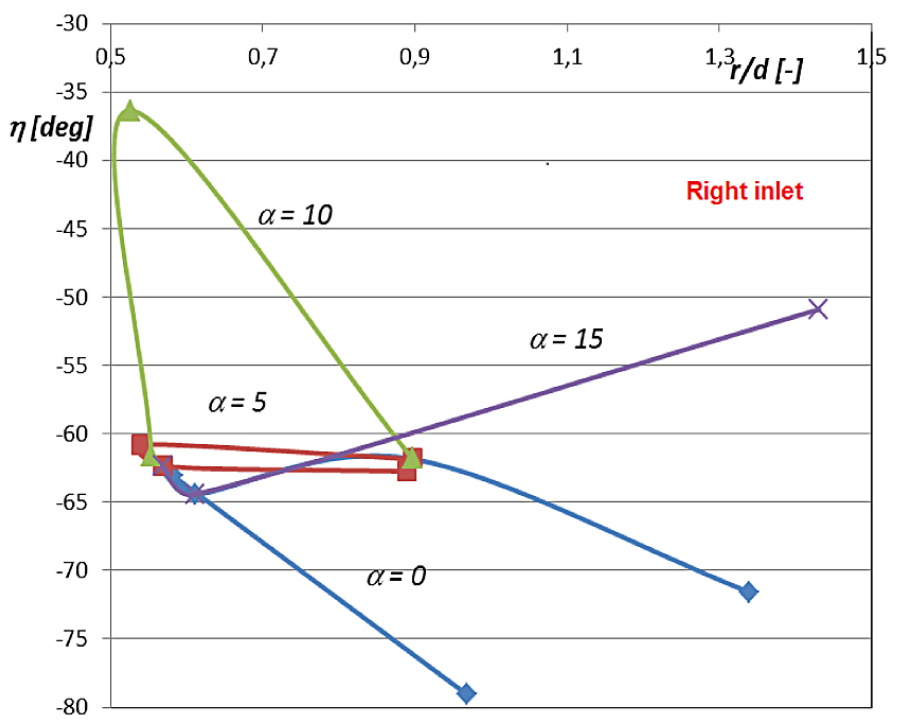

Fig. 11. Change in the stagnation point position angle $\eta$ vs. distance $r / d$ and gust direction angle $\alpha$, at $\mathrm{Ma}=0.0025$ 


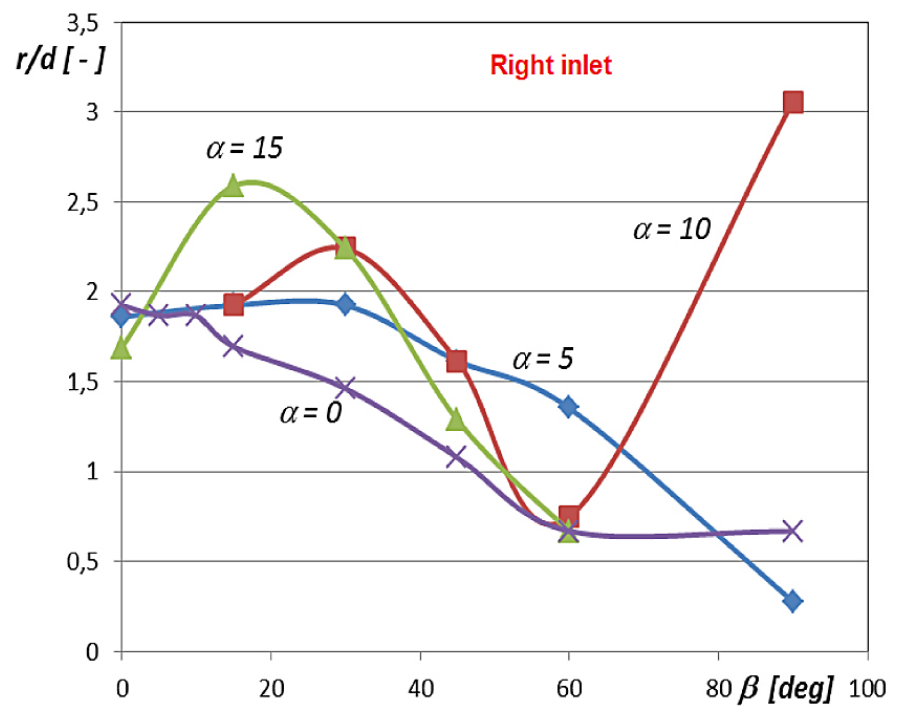

Fig. 12. Change in distance $r / d$ of the stagnation point position vs. gust direction $\beta$ and gust direction angle $\alpha$, for $\mathrm{Ma}=0.005$

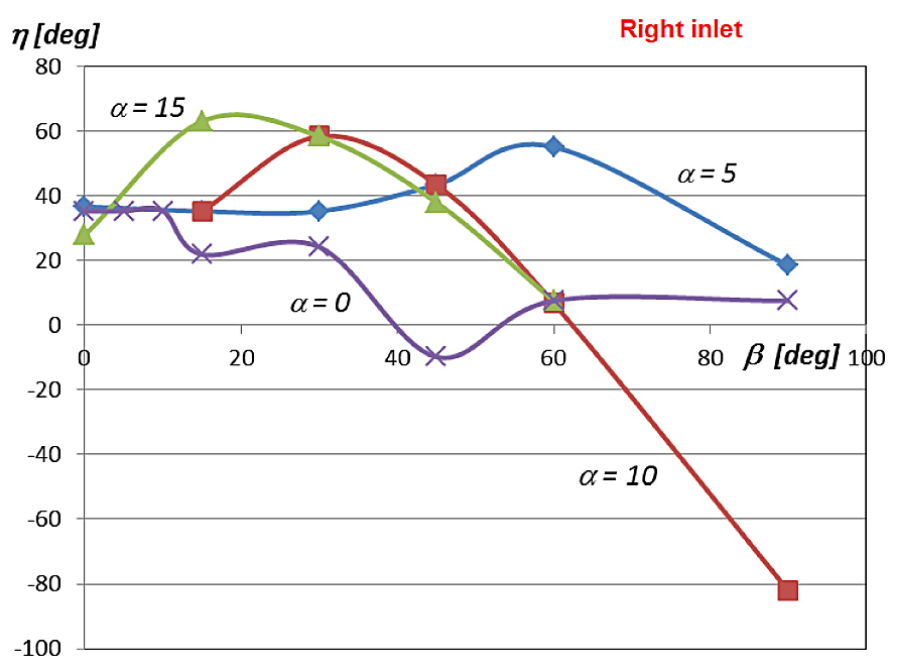

Fig. 13. Change in the stagnation point position angle vs. gust direction $\beta$ and gust direction angle $\alpha$, for $\mathrm{Ma}=0.005$

the gust with $\mathrm{M} \alpha=0.0025$. The zone of majority of stagnation points is within the belt the left part of which nears axis $r / d$ for $r / d=0.5 \div 1.0$ and $\eta=10^{\circ} \div-10^{\circ}$, and the right side reaches the area $r / d=2.2 \div 2.6$ and $\eta=59^{\circ} \div 61^{\circ}$.

\section{CONCLUSIONS}

The fuselage-shielded inlet model built for the purpose of this study was tested for the susceptibility to the vortex formation. Most importantly, based on the findings, one can see a tremendous potential regarding the application of the package to problems of this kind. The initial findings were very promising and established the basis for further, deeper numerical analyses into the changes in the stagnation point position as a function of changing conditions. A time-consuming analysis was conducted for 48 cases of varying gusts $(\mathrm{Ma}=0.0025$ and $\mathrm{Ma}=0.005)$, different gust inflow angles $\alpha\left(0^{\circ},-5^{\circ},-10^{\circ},-15^{\circ}\right)$ and gust direction angles $\beta\left(0^{\circ}, 15^{\circ}, 30^{\circ}, 45^{\circ}, 60^{\circ}, 90^{\circ}\right)$. The final outcome is a set of characteristics. On the one hand, these characteristics were created to investigate the impact of the above-mentioned parameters on the possibility of vortex formation, and on the other, to see whether it is possible to maintain the regularity of changes in the stagnation point position vs. changing Ma, $\alpha$ and $\beta$. On the basis of the findings, one can say that the regularity of stagnation point positions relative 


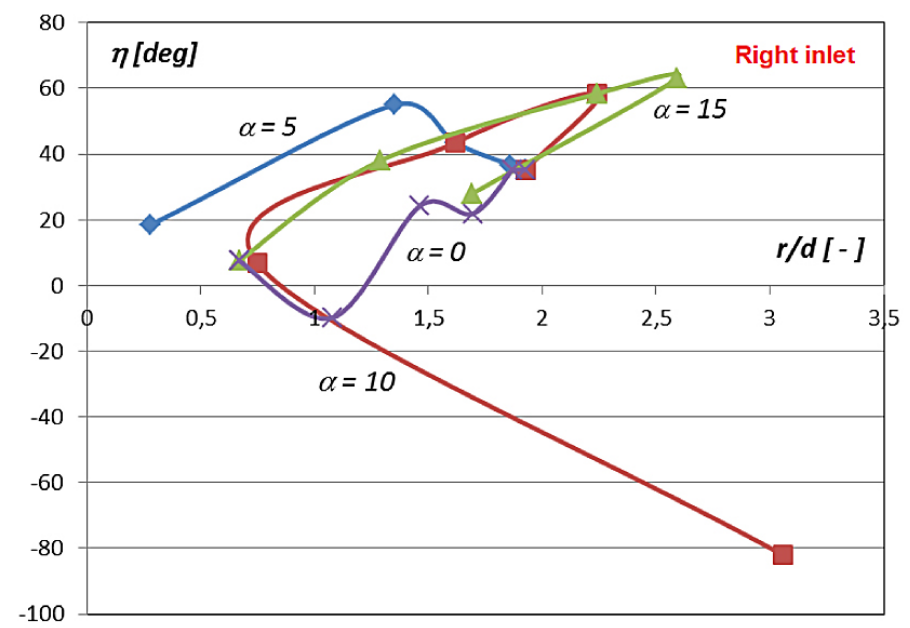

Fig. 14. Change in the stagnation point position angle vs. distance $r$ and gust inflow angle $\alpha$, for $\mathrm{Ma}=0.005$

to the linear parameter, i.e. the relative radius $r /$ $d$, is greater at lower gust values $(\mathrm{Ma}=0.0025)$ than it is at higher. However, a higher gust velocity increases the range of probability of vortex formation. The situation is opposite in the case of the position angle $\eta$, where an increase in velocity results in an increase in regularity of the characteristics of that angle along with the changes in the zone of formation relative to the longitudinal axis of the inlet system. As regards the second objective - an investigation into the zones of vortex formation as defined by the relative radius $r / d$ and position angle $\eta$ - one can notice that an increase in the gust on one side increased the area of possible vortex formation while systematising the phenomenon within a single belt-shaped zone.

The findings provide an interesting material for the analysis of susceptibility of the inlet system to the vortex formation vs. changing gust parameters. The authors intend to continue their numerical studies into the vortex phenomena in turbine jet engine systems, including the investigation into gradient sizes in vortex zones. In addition, work is being conducted to prepare a laboratory test bed for investigating the inlet systems susceptibility to the vortex formation to verify the findings from the numerical analyses.

\section{REFERENCES}

1. Elsner J.W.: Turbulencja przepływów. PWN Warszawa, 1987 [in Polish].

2. Gryboś R.: Podstawy mechaniki płynów. T. 2.
PWN Warszawa, 1998 [in Polish].

3. Kazimierski Z.: Podstawy mechaniki płynów i metod komputerowej symulacji przepływów. Politechnika Łódzka, Łódź, 2004 [in Polish].

4. Kozakiewicz A.: Analiza uszkodzeń turbinowych silników odrzutowych. Prace Instytutu Lotnictwa, Zagadnienia napędów lotniczych, 213, 2011, 224-234 [in Polish].

5. Liu H., Yi B., Wang C., Hui M.: Numerical simulations on nacelle inlet ground vortex under crosswind conditions. Aeroengine; Nanjing, China, 43(6), 2017.

6. Lumley J.L., Yaglom A.M.: A Century of Turbulence. Proc. VII European Turbulence Conference, Barcelona, 2000.

7. MacManus D.G, Slaby M.: Intake ground vortex and computational modelling of foreign object ingestion. The Aeronautical Journal, 119(1219), 2015.

8. Murphy J., MacManus D.: Inlet ground vortex aerodynamics under headwind conditions. Aerospace Science and Technology, 15, 2011.

9. Murphy J., MacManus D.: Ground vortex aerodynamics under crosswind conditions. Experiments in Fluids, 50, 2011.

10. Mihandoust A., Jahanian O., Hassanzadeh H.: Numerical simulation of inlet vortex near the inlet air duct of an aircraft engine in headwind condition. Modares Mechanical Engineering, 17(6), 2017 [in Persian].

11. Trapp L.G., da Motta Girardi R.: Crosswind Effects on Engine Inlets: The Inlet Vortex. Journal of Aircraft, 47(2), 2010.

12. Wilcox D.C.: Turbulence modeling for CFD. DCW Industries, 2006. 